\title{
PENGARUH PENGGUNAAN MEDIA AUDIO VISUAL TERHADAP PENINGKATAN PENGETAHUAN IBU TENTANG STUNTING DI PUSKESMAS RAWASARI KOTA JAMBI TAHUN 2019
}

\author{
The Effects of Use Audio Visual Media on Increasing Mother's Knowledge of Stunting in \\ Rawasari Health Center in Jambi City in 2019
}

\author{
Willia Novita Eka Rini ${ }^{1}$
}

${ }^{1}$ Program Studi Kesehatan Masyarakat Fakultas Kesehatan Masyarkat Universitas Jambi

\begin{abstract}
Abstrak
Latar belakang: Stunting merupakan masalah gizi kronis yang muncul sebagai akibat dari keadaan kurang gizi yang terakumulasi dalam waktu yang cukup lama. Stunting berdampak pada tingkat kecerdasan, kerentanan terhadap penyakit, dan menurunkan produktifitas. Untuk itu perlu adanya upaya pencegahan stunting melalui kegiatan promosi kesehatan yaitu dengan menggunakan media audiovisual. Penelitian ini bertujuan untuk mengetahui pengaruh penggunaan media audiovisual terhadap peningkatan pengetahuan ibu di Puskesmas Rawasari Kota jambi Tahun 2019. Metode: Jenis penelitian yang digunakan adalah quassy experimental dengan rancangan one group pretest-posttest design. Penelitian ini dilaksanakan di wilayah kerja Puskesmas Rawasari Kota Jambi dari bulan Juni-Juli 2019. Jumlah sampel dalam pnelitian ini sebanyak 40 sampel. Data diperoleh secara langsung wawancara responden dan pengukuran tingkat pengetahuan ibu sebelum dan sesudah diberikan penyuluhan menggunakan media audio visual. Uji statistik yang digunakan adalah uji tberpasangan. Hasil: Distribusi umur balita <2 tahun 24 responden (60\%), jenis kelamin balita perempuan sebesar 25 orang $(62,5 \%)$, dan respoden yang bekerja sebagai ibu rumah tangga sebesar 30 orang (75\%). Dari 40 orang responden, $20 \%$ responden memiliki pengetahuan baik pada saat pretest dan meningkat menjadi $55 \%$ responden pada saat posttest, $25 \%$ responden memiliki pengetahuan cukup tentang stunting pada saat pretest dan meningkat menjadi 32,5\% responden pada saat posttest, 55\% responden memiliki pengetahuan kurang pada saat pretest dan menurun menjadi $12,5 \%$ responden pada saat posttest. Hasil uji statistik menunukan ada perbedaan signifikan tingkat pengetahuan ibu sebelum dan sesudah diberikan penyuluhan tentang stunting dengan media audiovisual ditunjukan dengan nilai $\mathrm{p}=0.000$.
\end{abstract}

Kata Kunci : stunting, pengetahuan, media audio visual

\begin{abstract}
Background: Stunting is a chronic nutritional problem that arises as a result of a state of malnutrition that accumulates over a long period of time. Stunting affects the level of intelligence, susceptibility to disease, and decreases productivity. For this reason, it is necessary to prevent stunting through health promotion activities, namely by using audiovisual media. This study aims to determine the effect of the use of audiovisual media on increasing maternal knowledge in the Rawasari Health Center in Jambi City in 2019.Method: The type of research used was quassy experimental design with one group pretest-posttest design. This research was conducted in the working area of the Rawasari Health Center in Jambi City from June-July 2019. The number of samples in this study were 40 samples. Data were obtained directly by interviewing respondents and measuring the level of knowledge of mothers before and after counseling using audio-visual media. The statistical test used is a paired t-test. Results: Age distribution of toddlers <2 years 24 respondents $(60 \%)$, sex of toddlers girls by 25 people $(62.5 \%)$, and respondents who work as housewives by 30 people $(75 \%)$. Of the 40 respondents, $20 \%$ of respondents had good knowledge at the time of the pretest and increased to $55 \%$ of respondents at the time of the posttest, $25 \%$ of respondents had sufficient knowledge about stunting at the time of the pretest and increased to $32.5 \%$ of respondents at the time of the posttest, $55 \%$ of respondents lack of knowledge at the time of the pretest and decreased to $12.5 \%$ of respondents at the time of the posttest. Statistical test results show that there is a significant difference in the level of knowledge of mothers before and after counseling about stunting with audiovisual media, indicated by the value of $p=0,000$.
\end{abstract}

Keywords : stunting, knowledge, audiovisual media

Korespondensi: Willia

Email: willianovita95@gmail.com 


\section{PENDAHULUAN}

Stunting merupakan masalah gizi kronis yang muncul sebagai akibat dari keadaan kurang gizi yang terakumulasi dalam waktu yang cukup lama. Stunting atau pendek pada anak merupakan salah satu bentuk malnutrisi akibat keterbatasan keadaan sosial ekonomi secara keseluruhan di masa lampau. Stunting didefinisikan sebagai indeks tinggi badan menurut umur (TB/U) kurang dari minus dua standar deviasi ( $<-2$ SD) atau tinggi badan balita itu lebih pendek dari yang seharusnya bisa dicapai pada umur tertentu (Kemenkes 2010). Menurut World Health Organization (WHO) dalam Global Nutrition Targets 2025, stunting dianggap sebagai suatu gangguan pertumbuhan irreversibel yang sebagian besar dipengaruhi oleh asupan nutrisi yang tidak adekuat dan infeksi berulang selama 1000 hari pertama kehidupan.

World Health Organization (WHO) dalam Word Bank (2006) menyatakan bahwa suatu wilayah dikatakan memiliki masalah stunting ringan apabila prevalensi berada diantara 20\%$29 \%$, dikatakan sedang apabila berada diantara 30\%-39\%, dan dikatakan berat apabila $\geqslant 40 \%$. Prevalensi stunted di Provinsi Jambi berdasarkan Riskesdas tahun 2018 yaitu sebesar $30 \%$ sedangkan secara prevalensi nasional 29,9\%. Berdasarkan E-PPGBM Provinsi Jambi tahun 2018 ditemukan 7,8\% baduta gizi pendek di Provinsi Jambi.

Tingkat pengetahuan yang memadai merupakan dasar pengembangan daya nalar seseorang dan jalan untuk memudahkan menerima motivasi dan selanjutnya memberikan implikasi pada sikap dan perilaku seseorang. Berbagai metode dan alat telah dikembangkan dunia pendidikan dalam menyampaikan pesan yang bertujuan meningkatkan pengetahuan sikap dan keterampilan. Media tersebut berupa leaflet, buku saku dan video.

Media audio visual yang berupa video dapat digunakan sebagai media penyuluhan yang memiliki banyak keunggulan, salah satunya adalah dapat lebih mudah diterima karena mengaitkan langsung dengan indera penglihatan dan pendengarannya. Kurang lebih $75 \%$ sampai $87 \%$ dari pengetahuan manusia diperoleh/disalurkan melalui indera pandang, 13\% melalui indera dengar dan $12 \%$ lainnya tersalur melalui indera yang lain. ${ }^{1}$

Berdasarkan latar belakang tersebut, maka peneliti ingin melakukan penelitian tentang pengaruh penggunaan media audio visual terhadap peningkatan pengetahuan ibu di Puskesmas Rawasari Kota jambi Tahun 2019.

\section{Metode Penelitian}

Jenis penelitian yang digunakan adalah quassy experimental dengan rancangan one group pretest-posttest design. Dalam desain penelitian ini, sampel akan diberi pretest terlebih dahulu, setelah itu diberi perlakuan dalam hal ini yaitu media audio visual, dan setelah perlakuan akan diberi posttest. ${ }^{9}$

Penelitian ini dilaksanakan di wilayah kerja Puskesmas Rawasari Kota Jambi. Populasi pada penelitian ini adalah seluruh ibu yang memiliki balita di wilayah kerja Puskesmas Rawasari Kota Jambi. Teknik sampling yang digunakan dalam penelitian ini adalah probability sampling dengan besar sampel sebanyak 40 responden.

Teknik pengumpulan data berupa peneliti secara langsung mewawancarai responden dan melakukan pengukuran tingkat pengetahuan ibu sebelum dan sesudah diberikan penyuluhan menggunakan media audio visual. Dalam penelitian ini juga memerlukan data sekunder yang diperoleh dari Dinas Kesehatan Kota Jambi dan Puskesmas Rawasari.

Uji statistik yang digunakan adalah uji tberpasangan, merupakan uji parametrik (distribusi data normal) yang digunakan untuk mencari hubungan dua variabel atau lebih bila datanya berbentuk skala numerik, namun bila distribusi data tidak normal dapat digunakan uji Wilcoxon. ${ }^{3}$

\section{Hasil dan Pembahasan}

\section{Univariat}

\subsection{Karakteristik Responden}

Tabel 1. Karakteristik Responden menurut usia, jenis kelamin, dan pekerjaan ibu

\begin{tabular}{|c|c|c|c|}
\hline Variabel & Kategori & $\mathbf{n}$ & $\mathbf{\%}$ \\
\hline \multirow{2}{*}{ Umur balita } & $<2$ tahun & 24 & 60,0 \\
\cline { 2 - 4 } & $>2$ tahun & 16 & 40,0 \\
\hline Jenis & Perempuan & 25 & 62,5 \\
\hline
\end{tabular}




\begin{tabular}{|c|c|c|c|}
\hline kelamin balita & Laki-laki & 15 & 37,5 \\
\hline Pekerjaan & IRT & 30 & 75,0 \\
\cline { 2 - 4 } Ibu & $\begin{array}{c}\text { Pegawai } \\
\text { negeri/swasta }\end{array}$ & 10 & 25,0 \\
\hline
\end{tabular}

Sumber : Data Primer Terolah, 2019.

Pada tabel diatas menunjukkan bahwa $60 \%$ responden balita berumur $<2$ tahun sedangkan $40 \%$ responden balita lainnya berumur $>2$ tahun, $62,5 \%$ balita berjenis kelamin perempuan sementara $37,5 \%$ balita lainnya berjenis kelamin laki-laki, dan $75 \%$ pekerjaan ibu balita adalah Ibu Rumah Tangga sedangkan 25\% ibu balita lainnya bekerja sebagai pegawai negeri/swasta.

\subsection{Pengetahuan Ibu Pada Saat Pretest dan Posttest}

Berdasarkan hasil wawancara terhadap responden mengenai pengatuan ibu mengenai stunting dapat dilihat pada tabel berikut ini :

Tabel 2. Pengetahuan Ibu tentangStunting

Sumber : Data Primer Terolah, 2019.

Dari table diatas dapat dilihat dari total responden sebanyak 40 orang, bahwa $20 \%$ responden memiliki pengetahuan baik pada saat pretest dan meningkat menjadi $55 \%$ responden pada saat posttest, $25 \%$ responden memiliki pengetahuan cukup tentang stunting pada saat pretest dan meningkat menjadi 32,5\% responden pada saat posttest, $55 \%$ responden memiliki pengetahuan kurang pada saat pretest dan menurun menjadi $12,5 \%$ responden pada saat posttest.

\section{Bivariat}

\subsection{Hubungan Pengetahuan Ibu Pada Saat Pretest dan Posttest}

Tabel 3. Hasil Uji Normalitas Tingkat Pengetahuan ibu tentang stunting

Sumber : Data Primer Terolah, 2019.

Setelah dilakukan uji normalitas dengan menggunakan uji Kolmogorov-Smirnov menunjukkan bahwa semua data tidak terdistribusi secara normal ( $\mathrm{p}<0,05$ atau $0,000<$ 0,05). Sehingga uji perbandingan tingkat pengetahuan pretest dan posttest untuk kelompok intervensi dan kontrol yang digunakan adalah uji alternatif (Uji Wilcoxon Test).

\subsection{Hasil Uji WilcoxonT- Test}

Hasil uji statistik dengan Wilcoxon T-Test pada responden pretest dan posttest tingkat pengetahuan ibu sebelum dan sesudah diberikan penyuluhan tentang stunting dengan media audiovisual adalah sebagai berikut:

Tabel 4. Hasil Uji Perbandingan Tingkat Pengetahuan ibu tentang stunting Pretest dan Posttest (Wilcoxon T-Test)

\begin{tabular}{|l|l|l|l|l|l|l|}
\hline \multicolumn{2}{|l|}{ Tingkat Pengetahuan } & $\begin{array}{l}\text { Medi } \\
\text { an }\end{array}$ & $\begin{array}{l}\text { Median } \\
\text { difference }\end{array}$ & Min & max & $\begin{array}{l}\text { Nilai } \\
\text { P }\end{array}$ \\
\hline Intervensi & Pretest & 0,65 & 0,802 & 0 & 2 & 0,000 \\
\cline { 2 - 6 } & Posttest & 1,45 & 0,677 & 0 & 2 & 0 \\
\hline
\end{tabular}

Sumber : Data Primer Terolah, 2019.

Berdasarkan uji statistik dengan Wilcoxon $T$ Test pada responden pretest dan posttest

\begin{tabular}{|c|l|c|l|l|l|}
\hline \multirow{2}{*}{ Variabel } & \multirow{2}{*}{ Kategori } & \multicolumn{2}{|c|}{ Pretest } & \multicolumn{2}{c|}{ Posttest } \\
\cline { 3 - 6 } & & $\mathrm{n}$ & \multicolumn{1}{c|}{$\%$} & $\mathrm{n}$ & $\%$ \\
\hline $\begin{array}{l}\text { Pengatahuan } \\
\text { ibu }\end{array}$ & Baik & 8 & 20,0 & 22 & 55,0 \\
\cline { 2 - 6 } & Cukup & 10 & 25,0 & 13 & 32,5 \\
\cline { 2 - 6 } & Kurang & 22 & 55,0 & 5 & 12,5 \\
\hline \multicolumn{2}{|c|}{ Total } & 40 & 100,0 & 40 & 100,0 \\
\hline
\end{tabular}

didapatkan $\mathrm{p}=0.000$ atau $\mathrm{p}<0,05$ berarti terdapat perbedaan signifikan tingkat pengetahuan ibu sebelum dan sesudah diberikan penyuluhan tentang stunting dengan media audiovisual.

\section{PEMBAHASAN}

Pengaruh Penyuluhan Kesehatan Melalui Media Video Terhadap Peningkatan Pengetahuan Ibu

Hasil uji bivariat menggunakan Test Wilcoxon didapatkan nilai $\mathrm{p}=0,000$ atau $\mathrm{p}<$

\begin{tabular}{|c|c|}
\hline Kelompok & $\begin{array}{c}\text { Kolmogorov- } \\
\text { Smirnov }\end{array}$ \\
\hline $\begin{array}{c}\text { Tingkat Pengetahuan } \\
\text { Responden Pretest }\end{array}$ & 0,000 \\
\hline $\begin{array}{c}\text { Tingkat Pengetahuan } \\
\text { Responden Post-test }\end{array}$ & 0,000 \\
\hline
\end{tabular}

0,05 berarti terdapat perbedaan signifikan antara tingkat pengetahuan ibu sebelum dan sesudah 
diberikan penyuluhan. Dari hasil penelitian ini membuktikan bahwa penyampaian informasi tentang stunting dengan penyuluhan kesehatan melalui media audio visual dapat merubah tingkat pengetahuan ibu tentang stunting di wilayah kerja puskesmas rawasari.

Menurut Notoatmodjo (2005) pengetahuan merupakan hasil tahu dan terjadi setelah orang melakukan pengindraan terhadap obyek tertentu. Pengindraan terjadi melalui panca indra manusia, yaitu penciuman, penglihatan, pendengaran dan raba. Pengetahuan sendiri biasanya didapatkan dari informasi baik yang didapatkan dari pendidikan formal maupun informasi lain seperti radio, TV, internet, koran, majalah, penyuluhan dll.

Media penyuluhan merupakan salah satu komponen yang penting. Media audiovisual memang dianggap mampu untuk memberikan gambaran secara lebih jelas dan lebih menarik sebagai media untuk menyampaikan pesan penyuluhan kesehatan. Dimana dianggap mampu untuk menyampaikan pesan yang terkandung dalam media dengan baik kepada audience. $^{8}$

Menurut Maulana (2009), pancaindera yang banyak menyalurkan pengetahuan ke otak adalah mata (kurang lebih $75 \%$ sampai $87 \%$ ), sedangkan $13 \%$ sampai $25 \%$, pengetahuan manusia diperoleh dan disalurkan melalui pancaindera yang lain. Media seharusnya mampu merangsang atau memasukan informasi melalui berbagi indera. Semakin banyak yang dirangsang maka masuknya informasi akan semakin mudah. Perpaduan saluran informasi melalui mata yang mencapai $75 \%$ dan telinga $13 \%$ akan memberikan rangsangan yang cukup baik sehingga dapat memberikan hasil yang optimal. ${ }^{7}$

Hasil penelitian ini sejalan dengan Puspita (2012) yang menyatakan bahwa melalui media Pendidikan/penyuluhan yang digunakan dan cara penyampaian materi pendidikan dapat meningkatkan pengetahuan dan sikap seseorang. Media pendidikan berfungsi untuk mengerahkan indera sebanyak mungkin kepada suatu objek sehingga mempermudah persepsi. ${ }^{10}$

Hasil ini juga sejalan dengan penelitian Eko (2013), hasil penelitiannya diketahui bahwa terdapat efektivitas media audiovisual sebagai media penyuluhan kesehatan terhadap peningkatan pengetahuan ibu di dua rumah sakit kota malang. ${ }^{3}$ Penelitian ini didukung juga oleh hasil penelitian Wicaksono (2016) tentang pengaruh media audio visual terhadap pngetahuan, sikap dan perilaku ibu baduta di Puskesmas Kelurahan Johar Baru dengan hasil penelitian membuktikan bahwa media audio visual $(\mathrm{p}<0.05)$ memiliki pengaruh lebih tinggi dibandingkan dengan media lain. ${ }^{12}$

\section{KESIMPULAN DAN SARAN}

Berdasarkan hasil penelitian ini dan pembahasan, maka dapat dikemukakan kesimpulan sebagai berikut :

a. Karakteristik responden penelitian ini: umur balita $<2$ tahun 24 responden $(60 \%)$, jenis kelamin balita perempuan sebesar 25 orang $(62,5 \%)$, dan respoden yang bekerja sebagai ibu rumah tangga sebesar 30 orang $(75 \%)$.

b. Tingkat pengetahuan ibu tentang stunting: $20 \%$ responden memiliki pengetahuan baik pada saat pretest dan meningkat menjadi 55\% responden pada saat posttest, $25 \%$ responden memiliki pengetahuan cukup tentang stunting pada saat pretest dan meningkat menjadi $32,5 \%$ responden pada saat posttest, 55\% responden memiliki pengetahuan kurang pada saat pretest dan menurun menjadi $12,5 \%$ responden pada saat posttest.

c. Terdapat pengaruh penggunaan media audio visual terhadap peningkatan pengetahuan ibu tentang stunting di Puskesmas Rawasari Kota Jambi tahun 2019 yang signifikan dengan $\mathrm{p}=0,000$.

\section{Saran}

Berdasarkan hasil penelitian yang dapat dirumuskan hingga saat ini, saran yang dapat disampaikan adalah perlunya pembinaan secara berkesinambungan dari Pemerintah khususnya Instansi terkait yaitu Dinas Kesehatan Kota melalui Puskesmas untuk melakukan revitalisasi sarana-prasarana posyandu sehingga kegitan penyuluhan dapat ditingkatkan dengan penyuluhan menggunakan audio visual di posyandu-posyandu, meningkatkan upaya monitoring status gizi secara rutin setiap bulan melalui kegiatan Posyandu sehingga dapat mendeteksi dini kejadian stunting pada balita. 


\section{DAFTAR PUSTAKA:}

1. Arsyad A. 2006. Media Pembelajaran. Penerbit PT. Rajagrafindo Persada. Jakarta.

2. Alfridsyah., et all. 2013. Perbedaan Penggunaan Standar Baru Antropometri WHO-2006 dan Penilaian Status Gizi Pada Tenaga Gizi Pelaksana Di Kota Banda Aceh Tahun 2009. Buletin Penelitian Sistem Kesehatan - Vol. 16 No. 2 April 2013

3. Eko RK. 2013. Efektifitas audiovisual sebagai media penyuluhan kesehatan terhadap peningkatan pengetahuan dan sikap ibu dalam tatalaksana balita dengan diare di dua rumah sakit Kota Malang. Jurnal Ilmu Keperawatan.

4. Haryoko, Sapto. 2009. "Efektivitas Pemanfaatan Media Audio-Visual Sebagai Alternatif Optimalisasi Model Pembelajaran”. Jurnal Edukasi@Elektro (Volume 5, No 1 Tahun 2009, h.3).

5. Kementrian Kesehatan. 2010. Laporan Hasil Riset Kesehatan Dasar (Riskesdas) Indonesia Tahun 2010. Jakarta: Departemen Kesehatan Republik Indonesia.

6. Kementrian Kesehatan. 2018. Laporan Hasil Riset Kesehatan Dasar (Riskesdas) Indonesia Tahun 2018. Jakarta: Departemen Kesehatan Republik Indonesia.

7. Maulana, Heri. 2009. Promosi Kesehatan. Jakarta: EGC.

8. Mubarak, W.I. 2012. Ilmu Kesehatan Masyarakat Konsep dan Aplikasi Dalam kebidanan. Jakarta: Salemba Medika.

9. Notoatmodjo. 2005. Promosi kesehatan teori dan aplikasi. Jakarta: Rineka Cipta.

10. Puspita, I, D. 2012. Retensi Pengetahuan, Sikap, dan Perilaku Pasca Pelatihan Gizi Seimbang Pada Siswa
Kelas 5 dan 6 di 10 Sekolah Dasar Terpilih Kota Depok Tahun 2012. Universitas Indonesia.

11. Rahmawati Ira, Sudargo Toto, Paramastri Ira. Pengaruh Penyuluhan dengan Media Audio Visual terhadap Peningkatan Pengetahuan, Sikap dan Perilaku Ibu Balita Gizi Kurang dan Buruk di Kabupaten Kota Waringin Barat Propinsi Kalimantan tengah. The Indonesian Journal of Clinical Nutrition: Artikel Vol. 4 No.2

12. Wicaksono, Dipo. 2016. Pengaruh Media Audio-Visual MP-ASI Terhadap Pengetahuan, Sikap dan Perilaku Ibu Baduta Di Puskesmas Kelurahan Johar Baru. Jurnal Penelitian dan Pengabdian Masyarakat.

13. Zakaria, A. 2002. Strandart Teknis Media Penyuluhan Pertanian, Badan Pengembangan Sumber Daya Manusia Pertanian Departemen Pertanian. 